\title{
Trematodes with a reproductive division of labor: heterophyids also have a soldier caste and early infections reveal how colonies become structured
}

Ana E. Garcia-Vedrenne ${ }^{a, *}$, Anastasia C.E. Quintana ${ }^{b, c}$, Andrea M. DeRogatis ${ }^{b, d}$, Christina M. Dover ${ }^{a, e}$, Maribel Lopez ${ }^{a}$, Armand M. Kuris ${ }^{a, b}$, Ryan F. Hechinger ${ }^{a, f}$

${ }^{a}$ Department of Ecology, Evolution and Marine Biology, University of California, Santa Barbara, California 93106, USA

${ }^{\mathrm{b}}$ College of Creative Studies, University of California, Santa Barbara, California 93106, USA

${ }^{\mathrm{C}}$ Department of Marine Science and Conservation, Nicholas School of the Environment, Duke University, Durham, North Carolina 27708, USA

${ }^{\mathrm{d}}$ Department of Animal Science, University of California, Davis, California 95616, USA

e Virginia-Maryland College of Veterinary Medicine, Blacksburg, Virginia 24061, USA

${ }^{\dagger}$ Scripps Institution of Oceanography, Marine Biology Research Division, University of California, San Diego, La Jolla, California 92093, USA

${ }^{*}$ Corresponding author. Ana E. Garcia-Vedrenne, Tel.: +1-805-893-3998.

E-mail address: vedrenne@lifesci.ucsb.edu 


\section{Abstract}

Recent findings have extended the documentation of complex sociality to the Platyhelminthes, describing the existence of a reproductive division of labor involving a soldier caste among the parthenitae of trematode parasites. However, all species examined to date occupy high positions in trematode interspecific dominance hierarchies and belong to two closely related families, the Echinostomatidae and the Philophthalmidae (Superfamily Echinostomatoidea). Further, the two species documented as lacking soldiers also belong to the Echinostomatidae. Here, we examine four species of intermediate dominance, all belonging to the family Heterophyidae (Superfamily Opisthorchioidea): Euhaplorchis californiensis, Phocitremoides ovale, Pygidiopsoides spindalis and Stictodora hancocki, all of which infect the California horn snail, Cerithideopsis californica (=Cerithidea californica). We quantify morphology, distribution and behavior of rediae from fully developed colonies. We also provide information on colony structure for three developing heterophyid colonies to better understand colony development. We discuss the implications of our findings, particularly with respect to how they suggest alternatives to the conclusions of other researchers concerning the nature of trematode sociality. Our analyses of morphological, distributional and behavioral patterns of developed colonies indicate that these heterophyid trematodes have a non-reproductive caste whose function is defense of the colony from invading trematodes. Hence, a soldier caste occurs for species lower in dominance hierarchies than previously known, and is present in at least two superfamilies of digenean trematodes, suggesting that selection for a soldier caste may be much more common among the Trematoda than previously recognized.

Keywords: Sociality, Colony, Soldier caste, Defense, Rediae, Digenea, Trematoda 


\section{Introduction}

A complex social system has recently been documented in digenean trematodes (Hechinger et al., 2011; Leung and Poulin, 2011; Miura, 2012; Nielsen et al., 2014; Garcia-Vedrenne et al., 2016). As in the most complex animal societies (e.g. several types of insects (e.g., Wilson, 1971; Aoki, 1977; Crespi, 1992; Kent and Simpson, 1992; reviewed in Myles, 1999), snapping shrimp (Duffy, 1996), and naked mole-rats, (Jarvis et al., 1981)), the parthenita stages of some trematode species live in colonies with morphologically and behaviorally distinct reproductive and nonreproductive castes (Hechinger et al., 2011; Leung and Poulin, 2011; Miura, 2012; Nielsen et al., 2014; Garcia-Vedrenne et al., 2016). Although the non-reproducing caste might have some other roles (e.g. Lloyd and Poulin, 2012; Galaktionov et al., 2015), it is clear that a major role is defense of colonies (Hechinger et al., 2011; Miura, 2012; Mouritsen and Halvorsen, 2015; Garcia-Vedrenne et al., 2016).

Digenean trematode colonies are formed in the first intermediate host, usually a mollusk. The colony is initiated by a single founder larva (miracidium) that infects the host, metamorphoses and clonally produces large numbers of daughter parthenitae. Some trematode species have rediae: parthenitae that possess a muscular pharynx and a gut. Other species have sporocysts, which lack a pharynx and gut. Both kinds of parthenitae produce more parthenitae and then dispersive offspring (cercariae), which leave the colony to infect the next host in the life cycle.

Once established, the colony blocks host reproduction and takes control of the host's energy allocation to serve the needs of the colony, primarily diverting energy to parasite reproduction (Rothschild and Clay, 1952; Kuris, 1974; Baudoin, 1975; Hechinger et al., 2009; Lafferty and Kuris, 2009). The colony commonly occupies the gonad and/or digestive gland of the host, taking up a large portion of the host's soft tissue (10-50\%) (e.g., Hurst, 1927; Bernot and Lamberti, 2008; Hechinger et al., 
2009). Given their extensive use and control of host resources, such conditions would lead to intense competition should another trematode invade the same molluscan host.

Typically, when two trematode species infect the same host, one kills the other. These antagonistic interactions are hierarchical. Dominant species fend off invasions or displace established colonies of subordinate species. This displacement may be via chemical mechanisms (known for some species with sporocysts (Basch et al., 1969; Walker, 1979)), but it most commonly occurs via predation by rediae (Lim and Heyneman, 1972; Lie, 1973; Combes, 1982; Kuris, 1990; Sousa, 1993). Until recently, this antagonism had been considered to occur via the actions of "totipotent" rediae, those that both reproduce and defend the colony (Lim and Heyneman, 1972; Lie, 1973; Kuris, 1990; Sousa, 1993; but see Lie, 1969).

However, recent studies have shown that several trematode species have a division of labor involving a caste of non-reproducing soldiers that are specialized for defense (Hechinger et al., 2011; Leung and Poulin, 2011; Miura, 2012; Nielsen et al., 2014; Garcia-Vedrenne et al., 2016). Despite being smaller than reproductives, soldiers have relatively large pharynxes to attack and kill invaders. Only soldiers readily attack heterospecific and even conspecific enemies. The small size of these soldiers likely facilitates dispersion throughout the host body, supported by the fact that soldiers are more active and disproportionately common in areas of the host where invasions occur. Small rediae have been long observed in trematode infections (e.g. Stunkard, 1930; Kuntz and Chandler, 1956). However, small rediae are classically considered solely as being immature reproductives that are generated early in colony development, to periodically replace dying reproductives, and to permit colony growth as the host body increases in size. The discovery that these small rediae are not solely immatures, and sometimes represent a soldier caste, has 
expanded our perspective on the nature of trematode infections in first intermediate hosts and opened up new research avenues examining the ecology and evolution of complex sociality.

Hechinger et al. (2011) predicted that soldier castes would most likely evolve in trematode taxa that are typically dominant in interspecific hierarchies. To adequately test this and other hypotheses concerning the evolution of sociality among trematode species, it is necessary to quantify social structure for trematode species encompassing a range of dominance positions and that are spread throughout the trematode phylogenetic tree. Despite there being over 150 families of Trematoda (Cribb and Bray, 2011), all trematodes so far examined for social structure belong to two closely related digenean families: Echinostomatidae and Philophthalmidae (Superfamily Echinostomatoidea) (Hechinger et al., 2011; Leung and Poulin, 2011; Miura, 2012; Nielsen et al., 2014; Garcia-Vedrenne et al., 2016). Echinostomoids tend to occupy high positions in trematode dominance hierarchies (Lim and Heyneman, 1972; Lie, 1973; Kuris, 1990). This restricted taxonomic sampling also includes the two species explicitly shown to lack soldiers (GarciaVedrenne et al., 2016). Colony social structure has not been examined for species in any of the other trematode superfamilies.

Here, we examine four trematode species that belong to the Family Heterophyidae of the Superfamily Opisthorchioidea (Euhaplorchis californiensis, Phocitremoides ovale, Pygidiopsoides spindalis and Stictodora hancocki).These species form colonies in the California horn snail, Cerithideopsis californica (= Cerithidea californica). The California horn snail is host for a diverse trematode guild that is characterized by a fairly well-resolved interspecific dominance hierarchy (Kuris, 1990; Sousa, 1993; Hechinger, 2010). Five of the most dominant species in this hierarchy (all in the Superfamily Echinostomatoidea) have been documented to 
have soldiers. The heterophyids studied herein have an intermediate position in the dominance hierarchy (they are subordinate to the echinostomatids and philophthalmids, but can eliminate or prevent infections of other, more subordinate, species in the guild (Kuris, 1990)). We also compare colony structure of a few recent, developing heterophyid colonies to fully developed colonies to shed light on the nature of colony development. We discuss the implications of our results, including alternative interpretations concerning the nature of trematode sociality. Our analysis of morphology, distribution, behavior and colony development of these four heterophyid species indicates that they also have a soldier caste, and that trematode caste structure takes time to develop, becoming more pronounced with colony age.

\section{Materials and methods}

\subsection{Study system and sample collection}

California horn snails, Cerithideopsis californica (=Cerithidea californica), (Potamididae) were collected from Carpinteria Salt Marsh, Santa Barbara County, California, USA between July 2013 and May 2016. Snails were maintained in the laboratory for up to 7 weeks in mesh bags on running sea water tables until processing. Some infections were identified by inducing cercaria emergence, and then dissected. In other cases, the snails were dissected and, if infected with the appropriate species, immediately processed. We identified trematode species following Martin (1972) and additional unpublished observations.

We examined the four species that belong to the family Heterophyidae:

Euhaplorchis californiensis (EUHA), Phocitremoides ovale (PHOC), Pygidiopsoides spindalis (PYGI), and Stictodora hancocki (STIC). For simplicity and clarity, we will refer to each species by the codes formed by the first four letters of their genus, as above. 


\subsection{Redia morphology and distribution}

Snails were collected between July 2013 and October 2015. We targeted three to five colonies (snails) for each of the study species. All the trematode colonies examined were producing cercariae. We followed the methods described in Garcia-Vedrenne et al. (2016). Briefly, we dissected snails by carefully cracking the shell with a hammer and divided the body into three different regions: mantle, basal visceral mass (middle), and the gonad/digestive gland. To ensure unbiased sampling of individuals to depict size-frequency distributions, we used a grid and random numbers to randomly sample approximately 30 rediae from each snail region.

Sampled rediae were killed by immersion in hot water, fixed in $70 \%$ ethanol and mounted in glycerin. Digital pictures were taken with a Lumenera Infinity 3 camera mounted on an Olympus BX60 compound microscope. We measured body length and width to the nearest micron; we also measured pharynx width and length. We calculated total body and pharynx volumes by approximation to a cylinder.

We assigned each individual to a morph category based on the presence or absence of developing offspring, regardless of size. Rediae that lacked free germballs or later-stage embryos were classified as soldiers, while individuals that contained at least some late-stage embryos of cercariae or rediae were identified as mature reproductives. In some cases we found individuals that had early stage embryos; these were scored as immature reproductives. For statistical analyses, we have included these immature morphs in the reproductive category, unless otherwise 179 stated. 


\subsection{Colony development}

In November 2015, California horn snails were collected from Carpinteria Salt Marsh and checked for infection status. Uninfected snails were sprayed with paint and returned to the salt marsh in December 2015. In May 2016, the marked snails were collected and dissected. Three snails harboring newly established heterophyid colonies were found (such infections are readily identifiable because the mother sporocyst is still present in the basal visceral mass region, and the rediae have not yet filled up the gonadal space, and are generally creating more rediae compared to cercariae (A.E. Garcia-Vedrenne, personal observations)). Identification to species was not possible due the absence of developed cercariae. Although the exact age of the infection could not be determined, they were likely less than 5 months old. We organized the relative ages of the colonies from youngest (1) to oldest (3) as determined by the size, number and distribution of parthenitae, as well as the stage of development of the cercariae within them. Individual rediae were randomly sampled from the whole snail (we did not divide these into the three different regions). Morphology and classification was determined as described in Section 2.2.

\subsection{Attack trials}

We performed attack trials to compare behavioral specialization of soldier and reproductive castes. Experiments took place between June and November 2015, and during May 2016.

Snails harboring heterophyid colonies were dissected and bisected just anterior to the gonad. Reproductives were isolated from the gonad by teasing apart the tissues and pipetting out the individuals into a separate Petri dish with filtered sea water. To isolate soldiers, we first teased the tissues from the anterior part of the snail (mantle and basal visceral mass), and filtered the parasites and tissues using a 
$75 \mu \mathrm{m}$ filter. This concentrated the soldiers and helped remove most of the snail tissue and free-swimming cercariae. Soldiers were further isolated and concentrated by pipetting them out into a smaller Petri dish before setting up the attack trials.

For the attack trials, 96-well plates with concave bottoms were used to increase encounter rates. Rediae from one to three colonies (as available) of each tested species were presented with reproductive rediae from heterospecific colonies. Colonies of PHOC, PYGI and STIC were exposed to EUHA reproductives, following Hechinger et al. (2011) and Garcia-Vedrenne et al. (2016) because EUHA is one of the most common trematodes at the collection locality. To evaluate the attack rates of EUHA, reproductive individuals of the heterospecific STIC were used. For each replicate, we placed approximately 10 heterospecific rediae into a single well with sea water, followed by approximately 10 soldiers or 10 reproductives of the focal species. For each combination, we used two to four replicate wells. The wells were held for $90 \mathrm{~min}$ at ambient room temperature $\left(21-23^{\circ} \mathrm{C}\right)$. Each individual well was observed with a stereomicroscope for $20 \mathrm{~s}$. An attack was recorded whenever a redia was attached to another with its mouth, following Hechinger et al. (2011).

\subsection{Statistical analysis}

All statistical analyses were performed using R 3.1.3 (run with RStudio 0.98.1103; R Core Team (2014). R: A language and environment for statistical computing. $R$ Foundation for Statistical Computing, Austria. http://www.R-project.org/), or JMP Pro 12.0.0 (JMP Pro®, Version 12,. SAS Institute Inc., USA) . For morphological analyses, we used a mixed-effects general linear model (GLM) on natural logtransformed response data, and set colony identification (ID) as a random effect to model the relationship between soldier and reproductive total volume, pharynx volume, and pharynx/volume ratios. Interaction terms between colony and morph 
type were included in the model as needed. We examined residual plots and normal quantile plots to ensure meeting assumptions regarding data normality and homoscedasticity. Cochran-Mantel-Haenszel Chi-square tests were used to examine the relationship between rediae type and snail region, while controlling for colony ID. For the attack rates, we used a binomial regression with a logit link function and tested for the effects of redia type. Colony ID was set as random effect. $P<0.05$ was considered significant.

\section{Results}

\section{Morphology}

We processed a total of 2,067 parthenitae from the four species. We examined four colonies of EUHA, three of PHOC, three of PYGI, and five of STIC. General patterns were consistent among colonies and our statistical analyses include data from all colonies. However, for illustrative purposes, figures for one representative colony of each species are provided in the text. Additional figures and data are presented in Supplementary Figs. S1-S4 and Supplementary Table S1.

There was strong dimorphism among colony members for each of the four species. Soldiers were clear and transparent, while the tegument of reproductives had a light yellowish-orange pigmentation (Fig. 1A). Reproductives were consistently longer and wider (Fig. 1B), with no overlap in body volume (Fig. 1C). The sizefrequency distributions were clearly bimodal (Fig. 1C) and reproductives had, on average, a volume 28 times larger than soldiers for EUHA ( $\left.t_{504}=80.0, P<0.0001\right), 69 x$ for $\mathrm{PHOC}\left(\mathrm{t}_{618}=141.0, P<0.0001\right), 32 \mathrm{x}$ for $\mathrm{PYGl}\left(\mathrm{t}_{483}=98.7, P<0.0001\right)$, and $19 \mathrm{x}$ for STIC ( $\mathrm{t}_{445}=16.6, P<0.0001$ (pooling all rediae per species; Supplementary Table $\mathrm{S} 1$ shows results for individual colonies).

For three species, absolute pharynx sizes of reproductive morphs were not significantly different from those of soldiers, being 0.98 times that of a soldier for 
EUHA ( $\left.\mathrm{t}_{449}=-0.14, P=0.8893\right), 0.94 x$ for $\mathrm{PHOC}\left(\mathrm{t}_{554}=-0.72, P=0.4702\right)$, and $0.92 x$ for

260

261

262

263

264

265

266

267

268

269

270

271

272

273

274

275

276

277

278

279

280

281

282

STIC ( $\left.\mathrm{t}_{367}=-1.15, P=0.249\right)$ (Fig. 1C). However, for PYGI the size of the pharynx of the large reproductives was actually smaller than that of the soldiers $\left(0.87 x, t_{401}=-\right.$ 2.74, $P=0.0065$ ) (Fig. 1D).

Relative to body size, soldiers had substantially larger pharynxes than did reproductive morphs; being $31 \mathrm{x}$ larger for EUHA ( $\left.\mathrm{t}_{449}=26.7, P<0.0001\right), 71 \mathrm{x}$ for PHOC ( $\left.\mathrm{t}_{554}=20.1, P<0.0001\right), 31 \mathrm{x}$ for PYGI $\left(\mathrm{t}_{401}=12.5, P<0.0001\right)$, and $21 \mathrm{x}$ for STIC $\left(\mathrm{t}_{367}=17.3, P<0.0001\right)($ Fig. 1E).

Both reproductive and soldier parthenitae in these four heterophyids lacked collars and locomotory appendages (lappets), consistent with the long-known general morphology of this group.

\subsection{Caste ratios and distribution}

For the four species examined, most rediae were located in the gonadal region, but some were also found in the basal visceral mass and the mantle. The relative numbers of soldiers and reproductive rediae (caste ratios) varied between regions for each species (Table 1, Fig. 2, Supplementary Figs. S1-S4; EUHA: $X^{2}{ }_{1,508}=20.5, P<0.0001$; PHOC: $X^{2}{ }_{1,622}=32.5, P<0.0001 ; P Y G I: X^{2}{ }_{1,487}=26.9$, $P<0.0001$; and STIC: $\left.X^{2}{ }_{1,450}=26.2, P<0.0001\right)$. However, in all cases, soldiers were relatively more common in the anterior portion of the snail (basal visceral mass and mantle) compared to the gonad region.

Immature individuals were uncommon in mature colonies of all species (Fig.

2, Supplementary Figs. S1-S4, Supplementary Table S1). Of the total rediae examined from the four species infecting the California horn snail, 23 out of 2,067 were immature. Among colonies within species, the average (and range) proportion 
of immatures among all parthenitae examined was $0.8 \%(0-1.7 \%)$ for EUHA, $0.2 \%$ $(0-0.5 \%)$ for PHOC, $1 \%(0-1.6 \%)$ for PYGI, and $2.9 \%(0-7.2 \%)$ for STIC. The average (and range) proportion of immatures considering only reproductive morphs was $1.1 \%(0-2.8 \%)$ for EUHA, $0.4 \%(0-0.8 \%)$ for PHOC, $1.6 \%(0-2.8 \%)$ for PYGI, and $4.9 \%(0-9.5 \%)$ for STIC.

\subsection{Colony development}

We processed an additional 453 rediae from snails with newly established heterophyid colonies. Among these, the proportion of immature rediae was significantly different $\left(X^{2}=102.7, P<0.0001\right)$, ranging from $21 \%$ immatures in the oldest colony to $77 \%$ in the youngest colony (Table 2; age was determined by number and size of parthenitae, as well as the stage of development of cercariae inside them). The degree of bimodality of the size-frequency distributions increased as the colony matured (Fig. 3).

\subsection{Activity and attack rates}

For all species, soldiers qualitatively appeared more active than reproductive morphs. Reproductive individuals rarely moved when exposed to heterospecific parthenitae. In contrast, soldiers increased activity, stretching and contracting their bodies and probing heterospecific parthenitae with their mouths. In some cases, soldiers attached their mouths to heterospecific parthenitae (Fig. 4), sometimes pulling the heterospecific's tegument into the pharyngeal lumen. Similar to what has been reported for echinostomoid soldiers (West, 1961; Lloyd and Poulin, 2012;

Garcia-Vedrenne et al., 2016), soldiers of each species often formed clusters of two 
to seven individuals, adhering at the posterior ends of their bodies (Fig. 4B). This clustering behavior was rarely observed among the reproductive morphs.

In quantitative attack experiments (Fig. 5), reproductive rediae rarely attacked heterospecific rediae. Only $1 / 324$ reproductive rediae engaged in antagonism (0.3\%). No attacks by reproductive rediae were observed for EUHA (0/105), PHOC $(0 / 86)$ or PYGI $(0 / 32)$ in the experimental trials. Only $1 / 101(1 \%)$ STIC reproductive rediae was recorded attacking a EUHA reproductive. We note that one EUHA reproductive was seen attacking a STIC soldier from a dissected snail, outside the experimental trials (Fig. 4A).

In contrast, for two of the heterophyid species, soldiers more readily engaged in antagonism (Fig. 5). A total of 5/63 (7.9\%) EUHA soldiers attacked STIC reproductives $\left(X^{2}{ }_{1,14}=10.7, P<0.0001\right)$, and $28 / 91$ (30.8\%) STIC soldiers attacked EUHA reproductives $\left(X^{2}{ }_{1,60}=485.6, P<0.0001\right)$. However, only $1 / 62(1.6 \%)$ PHOC soldiers attacked an EUHA reproductive $\left(\mathrm{X}^{2}{ }_{1,12}=1.7, P=0.19\right)$, and no PYGI soldiers were seen engaging in antagonistic behavior $(0 / 22)\left(\mathrm{X}_{1,4}^{2}=0, P=1\right)$.

We also set up attack trials versus fellow colony members. In only one of the dissected colonies, we observed one STIC soldier out of 90 attach its mouth to a member of its own colony.

\section{Discussion}

The morphological aspects of the rediae in the four examined heterophyid species are generally consistent with the patterns previously observed for the echinostomoid trematodes having a soldier caste (Hechinger et al., 2011; Leung and Poulin, 2011; Miura, 2012; Nielsen et al., 2014; Garcia-Vedrenne et al., 2016). 
the fact that soldiers are much smaller than reproductive rediae, the pharynx size of both kinds of rediae greatly overlapped in size. The heterophyid soldiers examined here lack the collars and locomotory extensions that have been relatively pronounced in soldier rediae in the Echinostomatidae and Philophthalmidae (Hechinger et al., 2011; Leung and Poulin, 2011; Miura, 2012; Nielsen et al., 2014; Garcia-Vedrenne et al., 2016), clarifying that these features are not required to function as a soldier.

Garcia-Vedrenne et al. (2016) hypothesized that, for any given species with soldiers, developing infections would be dominated by rapidly growing reproductive rediae and characterized by unimodal size-frequency distributions. The sizefrequency distributions would become more bimodal as the colony matured. GarciaVedrenne et al. (2016) present data for one developing infection and five established infections of the echinostomatid Himasthla rhigedana that are consistent with that hypothesis.

Our observations on established and developing colonies of heterophyid trematodes further support this characterization of colony development. The sizefrequency distributions for the fully developed heterophyid colonies were strongly bimodal, with very few immature rediae, if any, bridging the gap between the two modes. In fact, these heterophyids appear to have the lowest proportion of immatures of any of the species yet examined (Hechinger et al., 2011; Leung and Poulin, 2011; Miura, 2012; Nielsen et al., 2014; Garcia-Vedrenne et al., 2016).

Despite this, one colony did stand out as having many immatures (see Supplementary Fig. S4); however, STIC 4 appears to have been a colony that was still becoming established, based on the small amount of mature cercariae observed at dissection, and the large number of reproductive rediae containing only earlystage cercariae. 

established and provide evidence for colony development. Although species identification and exact age were unknown, we know they belong to the Heterophyidae and that colonies were likely less than 6 months old. The relative ages of the colonies were inferred based on size, number and distribution of parthenitae, as well as the stage of development of the cercariae within them. In the youngest colony, the distribution was unimodal, and many immature rediae were present (Fig. 3, Table 2). The bimodality of the size-frequency distributions was more pronounced in the (putatively) older colonies. The number of immature rediae decreased, more reproductive rediae contained late-stage cercariae, and the number of soldiers increased. Hence, these observations lend further support to the hypothesized characterization of colony development given by Garcia-Vedrenne et al. (2016), and highlight the need for research on experimentally initiated colonies to carefully quantify the details of trematode colony development. soldier caste. They posit that the overall bimodality reported for redia size-frequency distributions is partly determined by a constraint of redia growth, whereby young rediae initially undergo cellular proliferation, resulting in very little growth for a period of time, followed by a rapid increase in size via cellular extension. This scenario is not consistent with the clear documentation of unimodal size-frequency distributions for several trematode colonies. First, several species with soldiers and strong bimodal size-frequency distributions in developed colonies actually have unimodal size-frequency distributions in early colony development. This is the case for the developing heterophyid colonies reported here, and for the developing colony of $H$. rhigedana described in Garcia-Vedrenne et al. (2016). In these developing colonies, the size-frequency distributions are dominated by immature reproductives with no 
evidence of arrested growth causing bimodality. Second, examination of established colonies from two species of echinostomatid trematodes that lack soldiers (Echinostoma liei in Garcia-Vedrenne et al. (2016), and Echinostoma nasincovae (= Echinostoma spiniferum) in Zikmundová, J. 2011. Is there a soldier cast in freshwater echinostome trematodes? B.S. Thesis. Faculty of Science, University of South Bohemia in České Budějovice, Czech Republic) consistently showed unimodal size-frequency distributions in established colonies. Garcia-Vedrenne et al. (2016) examined E. liei colonies of different ages. They found that although the proportion of immatures decreases with infection age, the size-frequency distributions are always unimodal. Further, non-reproductive individuals are never seen, consistent with their not having a soldier caste (Garcia-Vedrenne et al., 2016). Finally, we have observed similar unimodal size-frequency distributions in developed colonies for several species with sporocysts, and another redial species lacking soldiers (A.E. Garcia-Vedrenne, unpublished data for species infecting the California horn snail). The presence of these unimodal size-frequency distributions, including those in developing colonies of species with soldiers, confirms that a universal constraint for redia growth does not explain the bimodality characterizing developed colonies of trematodes with a soldier caste.

Galaktionov et al. (2016) also argue that the bimodality of the size-frequency distributions is explained by young rediae experiencing a developmental arrest, driven by density-dependent suppression of their growth by developed rediae. This does not conflict with the hypothesis that small rediae are soldiers. However, Galaktionov et al. (2016) do not attribute a defensive function for those small, developmentally arrested rediae. They evaluate these rediae solely as being a reserve of immatures that will ultimately grow to become reproductives. 
ability to mature, but the available data suggest the typical soldier does not transition to a reproductive morph. However, we still lack conclusive evidence for whether digenean trematode soldiers represent a permanent caste or a temporal caste. Intramolluscan development has not been well studied for heterophyids, and a careful investigation of colony development and of the progeny of reproductive rediae would shed the most light on the permanency of the soldier caste. However, similar to the evaluation of the data for Himasthla sp. B by Hechinger et al. (2010), the large numbers of heterophyid soldiers, coupled with the rarity of immatures, strongly supports the hypothesis that the transition from non-reproductive to reproductive is an infrequent occurrence.

Although the permanency of members of the soldier caste remains an open question, the notion that they lack a defensive function is contradicted by several other lines of evidence, including their morphology, distribution within the host, and, particularly, their attack behavior in vivo and in vitro.

The distribution of the heterophyid rediae is consistent with the patterns characterizing echinostomoid trematodes with soldiers (Hechinger et al., 2011; Leung and Poulin, 2011; Miura, 2012; Nielsen et al., 2014; Garcia-Vedrenne et al., 2016). Reproductives were mostly located in the visceral mass, particularly in the gonad region (Fig. 2, Supplementary Fig. S1-S4). On the other hand, soldiers comprised the majority of the individuals in the basal visceral mass, and particularly in the mantle (72-98\%). Hence, soldier and reproductive rediae of the four species were unevenly distributed throughout host tissues, with soldiers being more common at invasion fronts. This is consistent with the hypothesis that they are a defensive caste. 

attack enemies at greater rates than did reproductives. Although the reproductive rediae have the ability to attack with their mouthparts, they do so at much lower rates than their non-reproductive counterparts. Very few reproductive rediae $(0-1.6 \%)$ attacked heterospecific rediae, while the percentage of soldiers attacking was substantially higher: $8 \%$ of EUHA soldiers and $31 \%$ of STIC soldiers were observed engaging in aggressive interactions. Colonies of PHOC and PYGI were rarely encountered in our sampling, and hence fewer replicates of the attack trials were possible. The lack of attacks by the soldiers in these species might be related to smaller sample size, or that they are indeed less aggressive. Although no attacks were observed for these two heterophyid species, the other lines of evidence (morphology, distribution, etc.) are congruent with them having soldiers. This, together with the fact that attacks were observed for EUHA and STIC, is also consistent with the heterophyids having a non-reproductive soldier caste.

In addition to being more aggressive, the soldiers frequently attached to each other at their posterior ends, forming clusters (Fig. 4B). This behavior has previously been reported in soldiers in the Echinostomatidae and Philophthalmidae (West, 1961; Lloyd and Poulin, 2012; Garcia-Vedrenne et al., 2016). Garcia-Vedrenne et al. (2016) hypothesized this behavior could enhance attack rates in snail blood sinuses, providing leverage and enabling movement in all directions.

Also consistent with previous work, soldiers and reproductives of these four species were not generally observed to attack fellow colony members. In the attack trials, no reproductive rediae attacked fellow colony members, and only one STIC soldier was seen attaching to a colony member. This may have been a behavioral artifact of the dissection. 
Hence, these distributional and behavioral results indicate that there is a

461

462

463

464

465

466

467

468

469

470

471

472

473

474

475

476

477

478

479

480

481

482

483

484

485

defensive function for the small, non-reproductive rediae. Galaktionov et al. (2016)

recognize that "small" and "large" rediae have distinct behaviors and are not

randomly distributed throughout the host, suggesting that this is due solely to age-

related feeding preferences, conceiving this as a form of "niche segregation" unlikely

to be associated with the 'colony' defense against invaders. However, it is well

known that these trematode colonies can incur relatively high rates of invasion by

enemies in the field (Kuris, 1990; Sousa, 1993; Kuris et al., 1994; Lafferty et al.,

1994). Given that soldiers disproportionately attack these enemies in vitro, it is

parsimonious to attribute defensive function in vivo. Further, we have repeatedly

observed soldiers aggregating around and attacking invading trematodes in

dissections of mixed-species infections (A.E. Garcia-Vedrenne, R.F. Hechinger,

personal observations; first noted in Hechinger et al. (2010)). Attacking and killing

invading trematodes would increase the survivorship and reproductive output of trematode colonies.

Hechinger et al. (2011) predicted that trematode soldier castes would most likely evolve in situations of higher invasion risk, among species that infect longerlived hosts, and in taxa that are typically dominant in interspecific hierarchies. The California horn snail is long-lived (>8 years (Race, 1981)), and it hosts a species-rich guild of trematodes with a fairly well-resolved interspecific dominance hierarchy (Kuris, 1990; Sousa, 1993; Hechinger, 2010). Five of the most dominant species in this hierarchy (all echinostomoids) have soldiers (Hechinger et al., 2011; GarciaVedrenne et al., 2016). However, the four heterophyid species examined here occupy a middle position in the hierarchy, being subordinate to the echinostomoids but able to kill other, more subordinate species in the guild (Kuris, 1990). The morphological, distributional and behavioral evidence presented here indicates that 
these heterophyids also have soldiers. Hence, a soldier caste is more broadly

487 distributed throughout the trematode phylogenetic tree and among species lower in 488 dominance hierarchies than was previously known. The identification of soldiers in 489 the Superfamily Opisthorchioidea represents a doubling of the taxonomic range for 490 which soldiers have been documented. This suggests an independent evolution of 491 soldiers (or its loss) multiple times within the Trematoda, and indicates that selection 492 for a soldier caste may be much more common among digenean trematodes than 493 previously recognized.

495 Acknowledgements

We thank Alan C. Wood and Julia C. Buck for assistance in the laboratory and 497 in the field, and the University of California Carpinteria Salt Marsh Natural Reserve, 498 US, for access to field sites. Our research was supported by the US National 499 Science Foundation (NSF)/National Institutes of Health (NIH) Ecology of Infectious 500 Diseases program (OCE-1115965) and by a University of California Institute for 501 Mexico and the United States (UCMEXUS)- El Consejo Nacional de Ciencia y 502 Tecnología (CONACYT) fellowship to A.E.G-V. 


\section{References}

506

507

508

Aoki, S. 1977. Colophina clematis (Homoptera, Pemphigidae), an aphid species with 'soldiers'. Kontyu 45, 276-282.

Baudoin, M. 1975. Host castration as a parasitic strategy. Evolution 29, 335-352.

Basch, P. F., Lie, K. J., Heyneman, D. 1969. Antagonistic interaction between strigeid and schistosome sporocysts within a snail host. J. Parasitol. 753-758.

Bernot, R. J., Lamberti, G. A. 2008. Indirect effects of a parasite on a benthic community: An experiment with trematodes, snails and periphyton. Freshwater Biol. 53, 322-329.

Combes, C. 1982. Trematodes: antagonism between species and sterilizing effects on snails in biological control. Parasitology, 84, 151-175.

Crespi, B. J. 1992. Eusociality in Australian gall thrips. Nature. 359, 724-726.

Cribb, T. H., Bray, R. A. 2011. Trematode families and genera: have we found them all?. Trends Parasitol. 27, 149-154.

Duffy, J. E. 1996. Eusociality in a coral-reef shrimp. Nature. 381, 512-514

Galaktionov, K. V., Podvyaznaya, I.M., Nikolaev, K.E., Levakin I.A. 2015. Selfsustaining infrapopulation or colony? Redial clonal groups of Himasthla elongata (Mehlis, 1831) (Trematoda: Echinostomatidae) in Littorina littorea (Linnaeus)(Gastropoda: Littorinidae) do not support the concept of eusocial colonies in trematodes. Folia Parasitol. 62, 067.

Garcia-Vedrenne, A.E., Quintana, A.C., DeRogatis, A., Martyn, K., Kuris, A.M. Hechinger, R.F. 2016. Social organization in parasitic flatworms-four additional 

echinostomoid trematodes have a soldier caste and one does not. J. Parasitol. $102,11-20$

Hechinger, R. F. 2010. Mortality affects adaptive allocation to growth and reproduction: Field evidence from a guild of body snatchers. BMC Evol. Biol. 10, 136.

Hechinger, R. F., Lafferty, K. D., Mancini, F. T., Warner, R. R., Kuris, A. M. 2009. How large is the hand in the puppet? Ecological and evolutionary factors affecting body mass of 15 trematode parasitic castrators in their snail host. Evol. Ecol. 23, 651-667.

Hechinger, R. F., Wood, A. C., Kuris, A. M. 2011. Social organization in a flatworm: Trematode parasites form soldier and reproductive castes. Proc. R. Soc. B. 278, $656-665$.

Hurst, C.T. 1927. Structural and functional changes produced in the gastropod mollusk, Physa occidentalis, in the case of parasitism by the larvae of Echinostoma revolutum. UCalifornia Press. (USA) 29, 321-404

Jarvis, J. U. M., Series, N., May, N. 1981. Eusociality in a mammal: Cooperative breeding in naked mole-rat colonies. Science 212, 571-573.

Kamiya, T., O'Dwyer, K., Nuy, J., Poulin, R. 2013. What determines the growth of individual castes in social trematodes? Evol. Ecol. 27, 1235-1247.

Kamiya, T., Poulin, R. 2013. Caste ratios affect the reproductive output of social trematode colonies. J. Evolutionary Biol. 26, 509-516.

Kent, D. S.,Simpson, J. A. 1992. Eusociality in the Beetle Austroplatypus incompertus (Coleoptera: Curculiomdae). Naturwissenschaften 79, 86-87. 
Kuntz, R. E., Chandler, A.C. 1956. Studies on Egyptian trematodes with special reference to the heterophyids of mammals. II. Embryonic development of Heterophyes aequalis Looss. J. Parasitol. 42, 613-625.

Kuris, A. M. 1974. Trophic interactions: similarity of parasitic castrators to parasitoids. Q. Rev. Biol. 49: 129-148.

Kuris, A. 1990. Guild structure of larval trematodes in molluscan hosts: Prevalence, dominance and significance of competition. In Esch, G.W., Bush, A.O., Aho, J.M. (eds) Parasite communities: Patterns and processes. Chapman and Hall, London, U.K., p. 69-100.

Kuris, A. M., Lafferty, K. D. 1994. Community structure: larval trematodes in snail hosts. Annu. Rev. Ecol. Evol. Syst. 25, 189-217.

Lafferty, K. D., Kuris, A. M. 2009. Parasitic castration: The evolution and ecology of body snatchers. Trends Parasitol. 25, 564-572.

Lafferty, K. D., Sammond, D. T., Kuris, A. M. 1994. Analysis of larval trematode communities. Ecology 75, 2275-2285.

Leung, T. L. F., Poulin, R. 2011. Small worms, big appetites: ratios of different functional morphs in relation to interspecific competition in trematode parasites. Int. J. Parasitol. 41, 1063-1068.

Lie, K. J. 1969. Role of immature rediae in antagonism of Paryphostomum segregatum to Schistosoma mansoni and larval development in degenerated sporocysts. Z. Parasitenkd. 32, 316-323.

Lie, K. J. 1973. Larval trematode antagonism: principles and possible application as a control method. Exp. Parasitol. 33, 343-349. 
573

574

575

576

577

578

579

580

581

582

583

584

585

586

587

588

589

590

591

592

593

Lim, H. K., Heyneman, D. 1972. Intramolluscan inter-trematode antagonism: A review of factors influencing the host-parasite system and its possible role in biological control. Adv. Parasitol. 10, 191-268.

Lloyd, M. M., Poulin, R. 2012. Fitness benefits of a division of labour in parasitic trematode colonies with and without competition. Int. J. Parasitol. 42, 939-946.

Martin, W.E. 1972. An annotated key to the cercariae that develop in the snail Cerithideopsis californica. Bull. - South. Calif. Acad. Sci. 71, 39-43.

Miura, O. 2012. Social organization and caste formation in three additional parasitic flatworm species. Mar. Ecol. Prog. Ser. 465, 119-127.

Mouritsen, K. N., Halvorsen, F.J. 2015. Social flatworms: the minor caste is adapted for attacking competing parasites. Mar. Biol. 162, 1503-1509.

Myles, T.G. 1999. Review of secondary reproduction in termites (Insecta: Isoptera) with comments on its role in termite ecology and social evolution. Sociobiology 33, 793-801.

Nielsen, S. S., Johansen, J., Mouritsen, K. N. 2014. Caste formation in larval Himasthla elongata (Trematoda) infecting common periwinkles Littorina littorea. J. Mar. Biol. Assoc. U. K. 94, 917-923.

Race, M. S. 1981. Field ecology and natural history of Cerithidea californica (Gastropoda: Prosobranchia) in San Francisco Bay. Veliger 24, 18-27.

Rothchild, M., Clay, T. 1952. Fleas, Flukes, and Cuckoos: A Study of Bird Parasites. Philosophical Library, New York xiv, 304. 
594 Sousa, W. P. 1993. Interspecific antagonism and species coexistence in a diverse 595 guild of larval trematode parasites. Ecol. Monograph. 63, 103-128.

596 Stunkard, H. W. 1930. The life history of Cryptocotyle lingua (Creplin), with notes on 597 the physiology of the metacercariae. J. Morphol. 50, 143-191.

598 Walker, J. C. 1979. Austrobilharzia terrigalensis: A schistosome dominant in 599 interspecific interactions in the molluscan host. Int. J. Parasitol.9, 137-140.

600 West, A.F. 1961. Studies on the biology of Philophthalmus gralli Mathis and Leger, 601 1910 (Trematoda: Digenea). Am. Midl. Nat. 66, 363-383

602 Wilson E. O. 1971. The insect societies. Harvard University Press, Cambridge, 603 Massachusetts.

604 605 
Fig. 1. Morphological attributes of redia morphs for each of the four species of examined heterophyid trematodes. Data are of a single, representative colony, but statistical analyses used data from all colonies and Supplementary Table S1, and Supplementary Figs. S1-S4 include figures for each colony examined. (A) Photographs of representative redia morphs: soldiers on the left, reproductives on the right. Scale bar $=200 \mu \mathrm{m}$. (B) Body width to body length relationships. (C) scale for $Y$ axes.

Fig. 2. Proportion of different morphs found in the three snail body regions: the mantle, basal visceral mass and gonad (and digestive gland). Data are of a single, representative colony, but analyses used data from all colonies and Supplementary Table S1, and Supplementary Figs. S1-S4 include figures for all colonies. Numbers in boxes indicate the total number of rediae sampled from the given region.

Fig. 3. Morphological attributes of developing heterophyid colonies. Colony 1 is inferred as being the youngest, Colony 3 as the oldest. (A) Body width to body length relationships. (B) Frequency distributions of body volume for randomly sampled rediae. Note the $\log _{10}$ scale of $X$ axes. (C-D) Box plots indicating median (line), interquartile range (box) and values that are within $1.5^{*}$ interquantile range 
631 (whiskers) of data for (C) absolute pharynx volume and (D) pharynx volume relative 632 to body volume. Note the $\log _{10}$ scale for $Y$ axes.

634 Fig. 4. Examples of trematode soldier attack and activity. Individuals attacking are 635 indicated by black arrows. (A) Attacks between Stictodora hancocki (STIC) soldiers 636 and Euhaplorchis californiensis (EUHA) reproductives. (B) STIC and EUHA soldiers 637 attacking each other. Note also soldiers adhering to each other at their posterior ends. Scale bar $=200 \mu \mathrm{m}$.

640 Fig. 5. Attack rates of soldiers and reproductives on heterospecific reproductive rediae for each of the four heterophyid species from the California horn snail. One to 642 three colonies (as available) of each focal species were used (represented by the different shapes and colors). For Euhaplorchis californiensis, the heterospecific 644 species used was Stictodora hancocki, while Phocitremoides ovale, Pygidiopsoides 645 spindalis, and Stictodora hancocki were exposed to colonies of Euhaplorchis 646 californiensis. Points indicate the proportion of individuals observed attacking for 647 each replicate well (two to four replicates for each combination), box plots indicate 648 median (line), interquartile range (box) and values that are within 1.5 * interquantile 649 range (whiskers) of data. 
652 Table 1. Percentage of parthenitae that are soldiers, by host body region. Actual

653 counts can be found in Supplementary Table S1 and Supplementary Figs. S1-S4.

\begin{tabular}{lcccc}
\hline & \multicolumn{4}{c}{ Average (and range) percentage of soldiers among colonies } \\
& EUHA & PHOC & PYGI & STIC \\
\hline Mantle & $79(50-100)$ & $92(89-94)$ & $72(57-88)$ & $98(89-100)$ \\
Basal Visceral Mass & $47(6-69)$ & $80(71-95)$ & $55(25-71)$ & $79(42-97)$ \\
Gonad & $8(3-17)$ & $14(8-24)$ & $9(4-16)$ & $9(0-17)$ \\
\hline
\end{tabular}

654 EUHA, Euhaplorchis californiensis; PHOC, Phocitremoides ovale; PYGI, Pygidiopsoides

655 spindalis; STIC, Stictodora hancocki.

656 
657 Table 2. Percentage of parthenitae of each morph type in three newly established 658 heterophyid colonies. Colony 1 is the youngest colony and Colony 3 is the oldest 659 colony.

660

\begin{tabular}{lccc}
\hline & 1 & 2 & 3 \\
\hline Reproductive & $6 \%$ & $47 \%$ & $60 \%$ \\
Immature & $77 \%$ & $29 \%$ & $21 \%$ \\
Soldier & $17 \%$ & $24 \%$ & $19 \%$ \\
$n$ sampled & 83 & 143 & 226 \\
\hline
\end{tabular}

661

662 
Soldier $\Delta$ Immature $\square$ Reproductive

Euhaplorchis californiensis

(EUHA)

A
Phocitremoides

ovale

(PHOC)

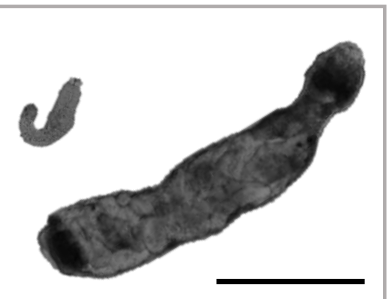

Pygidiopsoides spindalis

(PYGI)

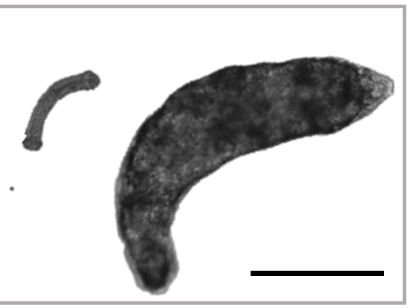

Stictodora hancocki

(STIC)

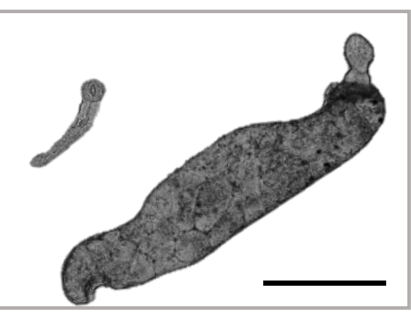

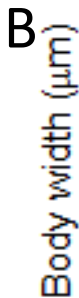
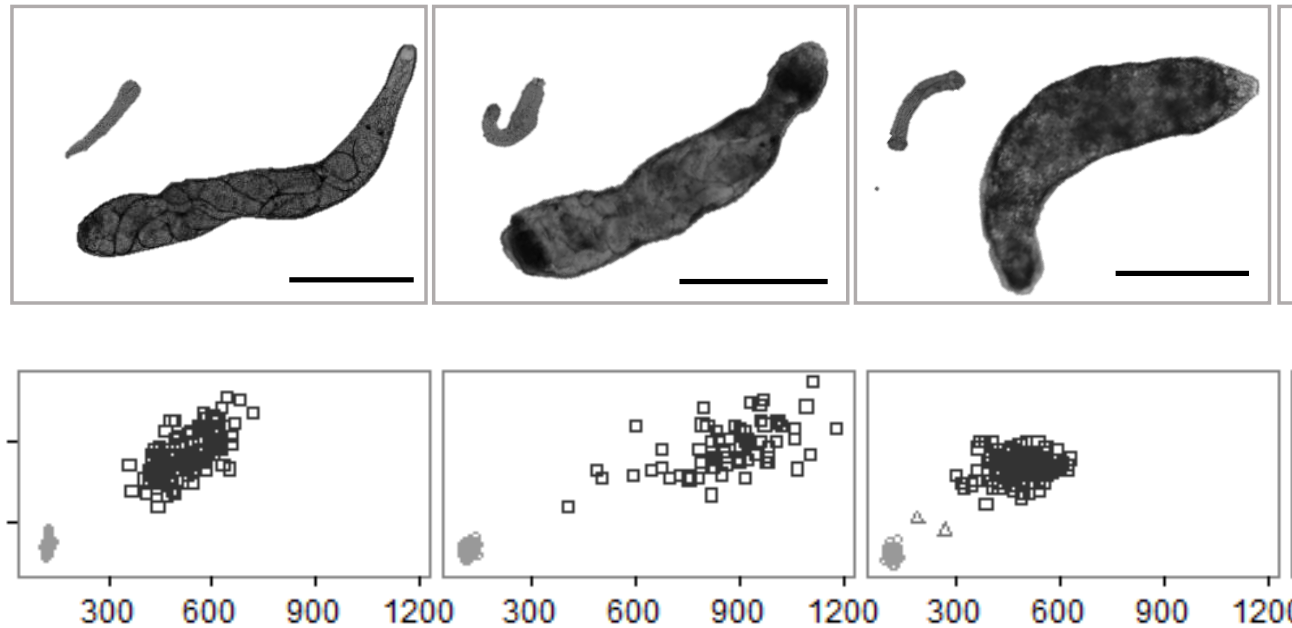
Body length $(\mu \mathrm{m})$

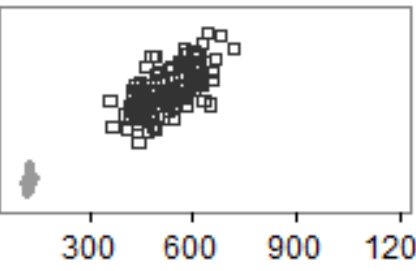

C
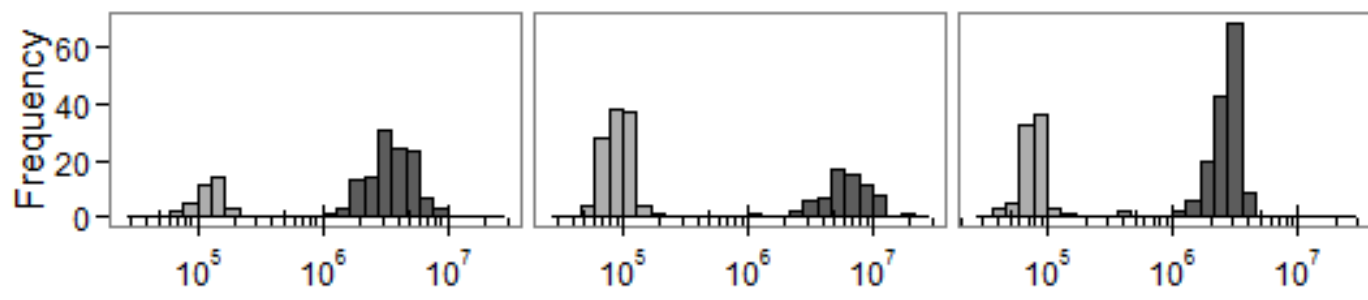

$\begin{array}{lll}10^{5} & 10^{6} & 10^{7}\end{array}$

$\begin{array}{lll}10^{5} & 10^{6} \quad 10^{7}\end{array}$

Body volume $\left(\mu \mathrm{m}^{3}\right)$

D

(5)

$\mathrm{E}$

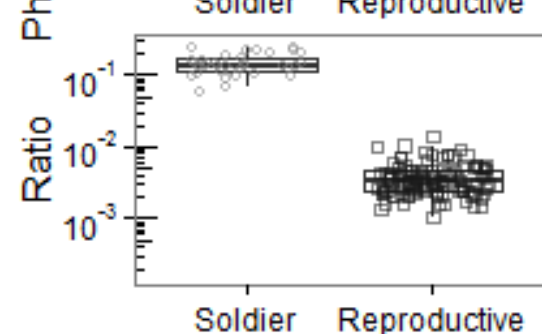

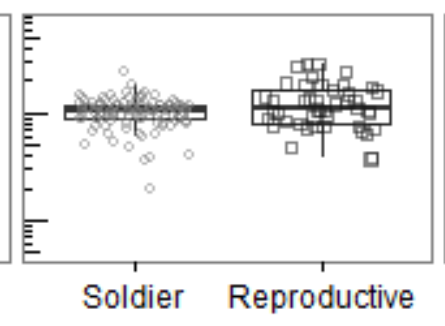

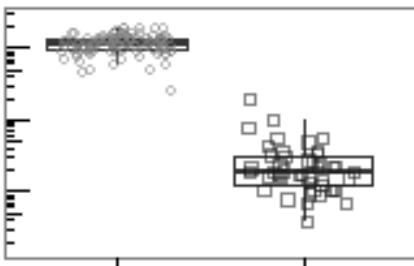

Soldier
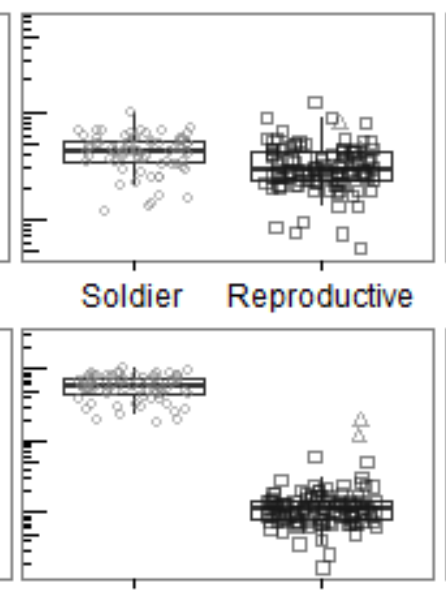

Soldier

Reproductive

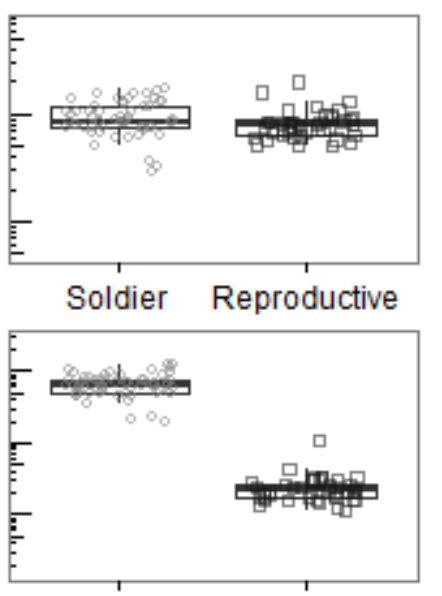

Soldier Reproductive 
Euhaplorchis californiensis

(EUHA)

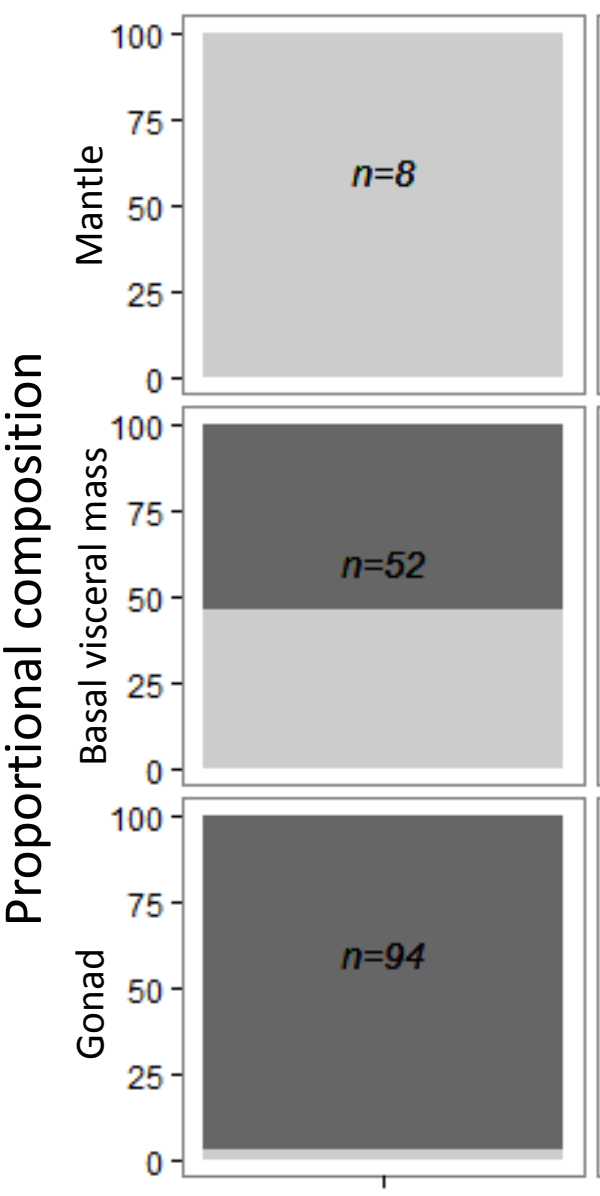

Phocitremoides ovale (PHOC)

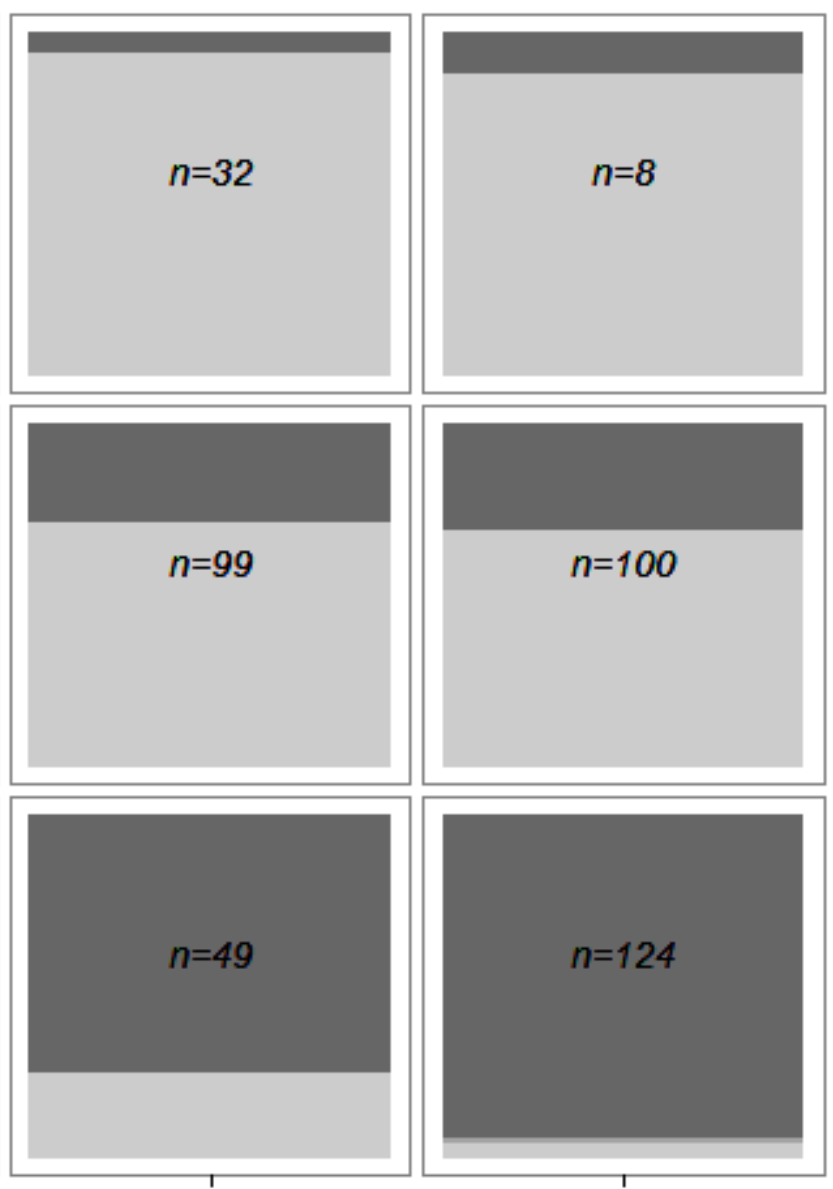

Stictodora hancocki

(STIC)

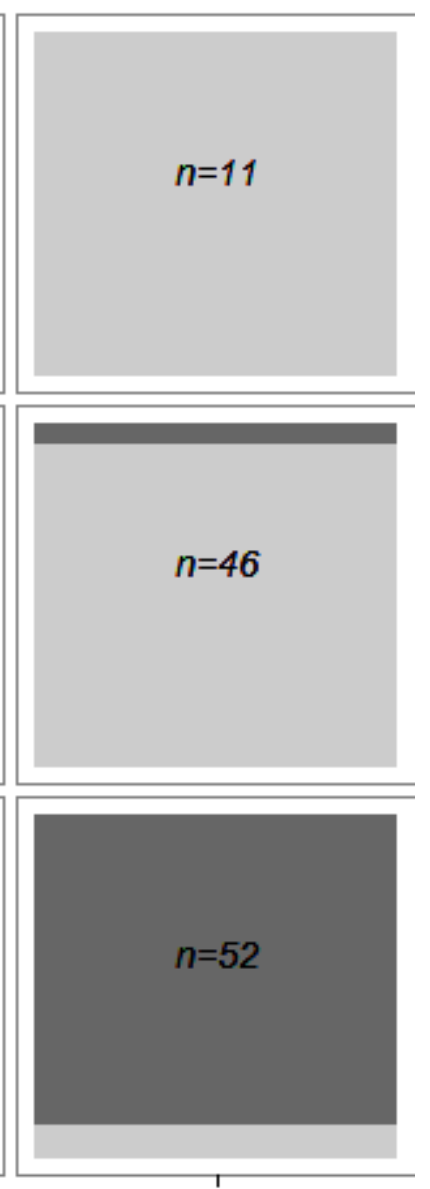

\section{Type Soldier Immature Reproductive}




\section{Soldier $\Delta$ Immature $\square$ Reproductive}
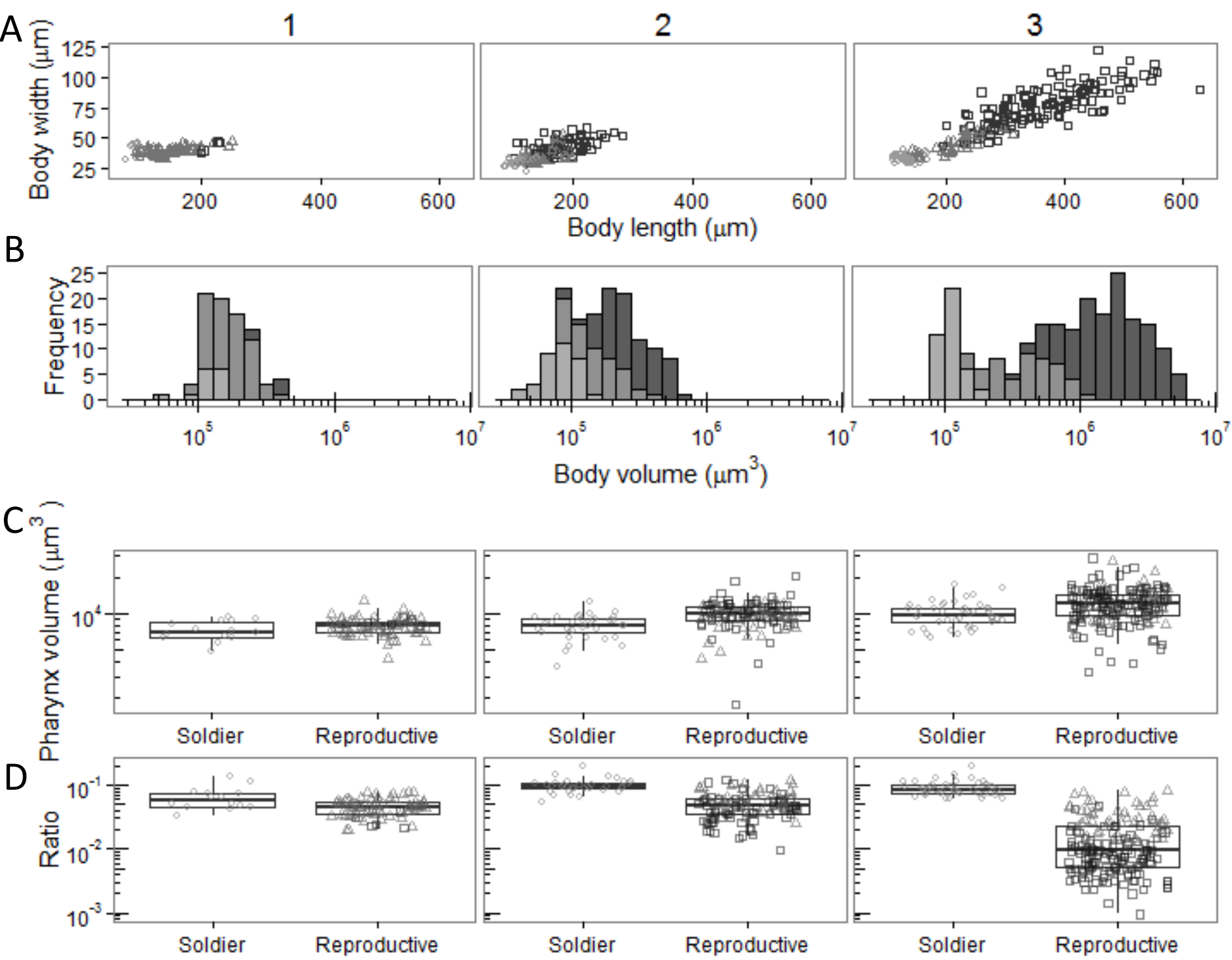


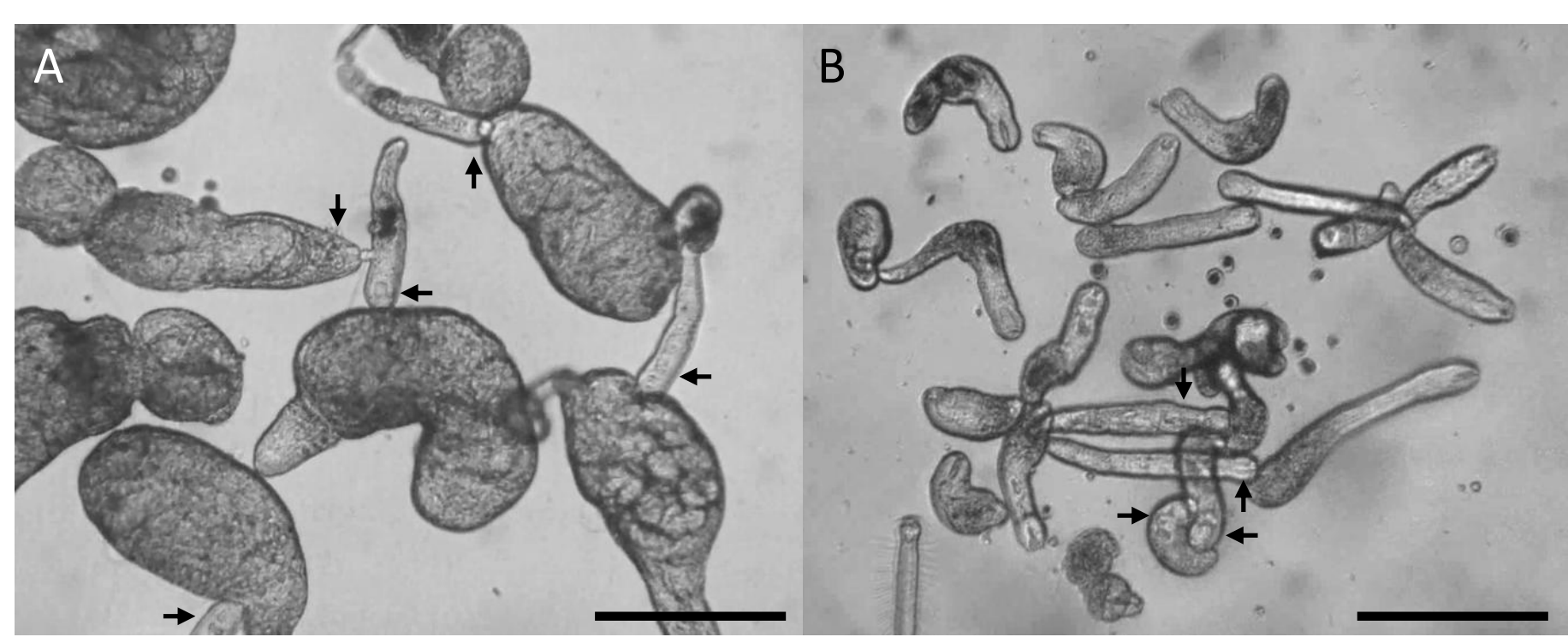




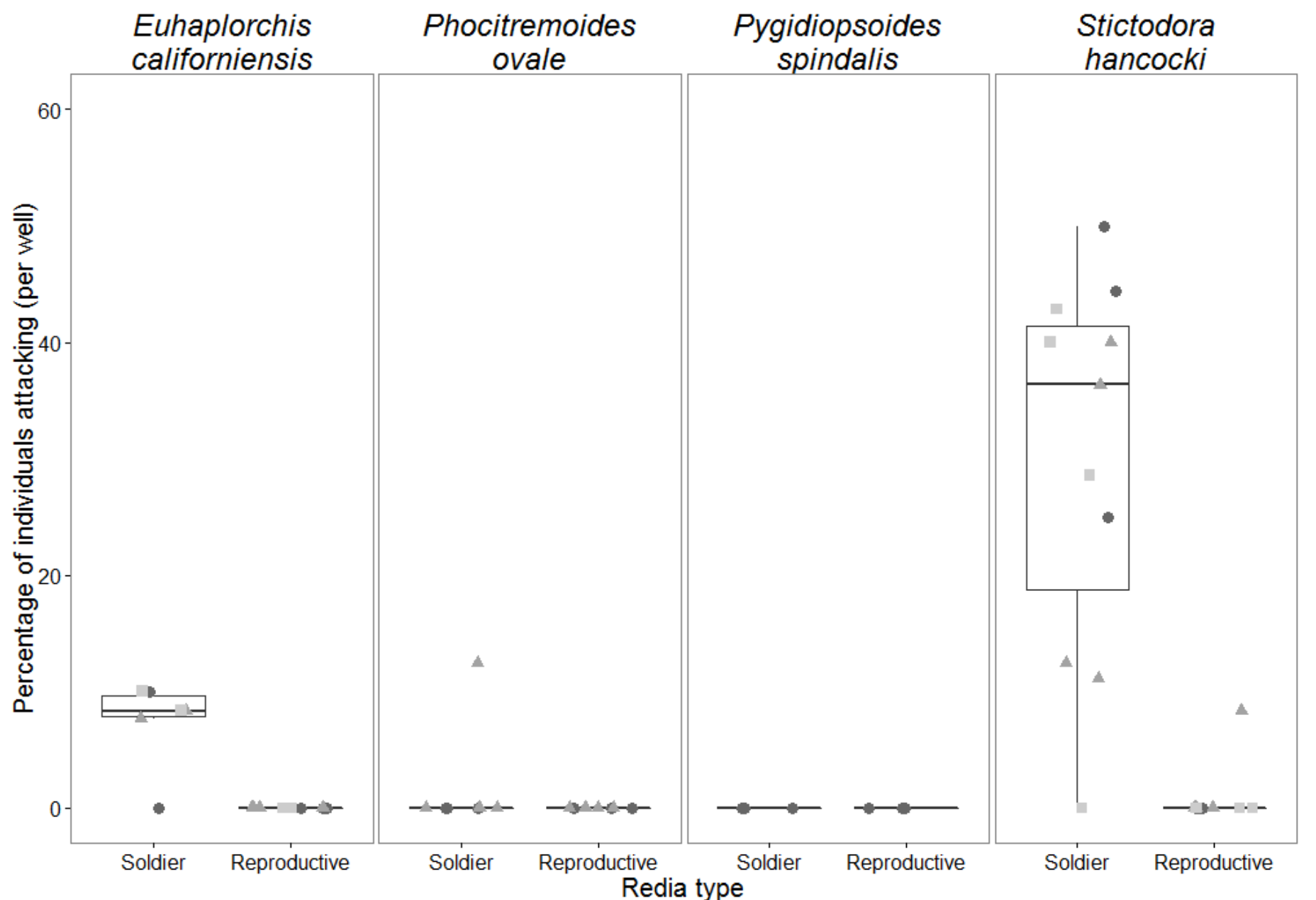

